\title{
Os Aspectos Psicológicos da Criança e do Adolescente na Adoção Tardia
}

\author{
Juliana Fernanda de Barros ${ }^{1}$ \\ ${ }^{1}$ Universidade Estadual Paulista Júlio de Mesquita Filho, \\ SP, Brasil.
}

\author{
Priscila Weiler Ribeiro ${ }^{2}$ \\ ${ }^{2}$ Faculdades Integradas de Três Lagoas, \\ MS, Brasil.
}

\author{
Lorena de Freitas Souza ${ }^{2}$ \\ ${ }^{2}$ Faculdades Integradas de Três Lagoas, \\ MS, Brasil.
}

Resumo: Em razão do número significativo de crianças maiores e adolescentes disponíveis para o processo de adoção no Cadastro Nacional de Adoção, e de a idade representar um fator de restrição e obstáculo para os pretendentes à adoção, torna-se necessário desmistificar as crenças enraizadas sobre adoção tardia. Pensando nessas questões, o presente estudo objetiva compreender os aspectos psicológicos e comportamentais das crianças e dos pais por adoção, comumente presentes no período de adaptação e convivência pós-adotiva, e analisar as atitudes dos pais diante dos obstáculos, observando a eficácia da preparação necessária aos pretendentes à adoção. Para tanto, a metodologia adotada consistiu inicialmente em embasar teoricamente a adoção tardia e suas fases de adaptação, com fundamentação psicanalítica, para a compreensão abrangente do assunto, e em uma pesquisa de campo com dois casais, pais por adoção que se encontravam no período de convivência de seis meses a um ano, para coletar dados relevantes e os correlacionar com a teoria. Por meio dos resultados obtidos, foram apontados os estágios de convivência e os aspectos psicológicos envolvidos nesse processo, bem como a importância de os pretendentes à adoção se instrumentalizarem com informações e se prepararem para a filiação afetiva. Assim, mesmo com todas as dificuldades que possam surgir no processo de adaptação na adoção tardia, em virtude de fatores como idade, preconceitos, mitos e histórico prévio de vida da criança, conclui-se que o afeto e a adoção recíproca prevalecem a qualquer desafio e que, se a experiência da adoção tardia for bem orientada, pode apresentar excelentes resultados.

Palavras-chave: Adoção Tardia, Estágios de Convivência, Psicanálise.

\section{Psychological Features of Late-Adopted Children and Adolescents}

\begin{abstract}
Before the significant number of older children and adolescents available for adoption in the National Adoption Register, and considering age as both a restriction factor and an obstacle, rooted beliefs concerning late adoption must be demystified. In this scenario, this study aimed to understand the psychological and behavioral features of children and their adopting parents during the adjustment period soon after adoption, besides analyzing parents' attitudes toward obstacles in light of the necessary preparation on the part of couples intending to adopt. Based on psychoanalytical principles, this study first sets the theoretical foundations of late adoption and its adjustment phases to reach a comprehensive understanding of the issue. To collect data and relate them to the underlying theory, a field research was conducted with two adopting couples in the adjustment period, which ranges from six months to a year. The results indicate the adjustment phases and psychological features underlying this process, besides stressing the importance of parents who intend to adopt for searching for information
\end{abstract}


on the issue and preparing themselves for an affective adoption. Despite the difficulties in late-adoption adaptation - due to age, prejudices, myths, and the previous lives of children, affection and mutual adoption can overcome any challenges that may arise. Moreover, if the late adoption process is adequately guided, it may present excellent results.

Keywords: Late Adoption, Familiarity Phases, Psychoanalysis.

\title{
Los Aspectos Psicológicos del Niño y del Adolescente en la Adopción Tardía
}

\begin{abstract}
Resumen: Debido al número significativo de niños mayores y adolescentes disponibles para el proceso de adopción en el Catastro Nacional deAdopción, y siendo la edad un factor de restricción y obstáculo para los adoptantes, es necesario desmitificar las creencias en relación a la adopción tardía. En este sentido, el presente trabajo tiene por objeto comprender los aspectos psicológicos y comportamentales de los niños y de los padres por adopción, comúnmente presentes en el período de adaptación y convivencia postadoptiva, así como analizar las actitudes de los padres ante a los obstáculos, observando la eficacia de la preparación necesaria para los aspirantes a adopción. Para ello, la metodología adoptada consistió inicialmente en basar teóricamente la adopción tardía y sus fases de adaptación, con fundamentación psicoanalítica, para una comprensión más amplia del asunto, y una investigación de campo con dos parejas, que son padres por adopción entre seis meses a un año, para recoger datos relevantes y correlacionarlos con la teoría. Los resultados apuntan las etapas de convivencia y los aspectos psicológicos que involucran este proceso, así como la importancia de los aspirantes a adopción para conseguir informaciones y prepararse para la filiación afectiva. Incluso con todas las dificultades que puedan surgir en el proceso de adaptación en la adopción tardía, en virtud de la edad, de los prejuicios, mitos y por el histórico previo de vida que el niño carga, se concluye que el afecto y la adopción recíproca prevalecen ante cualquier desafío y que si bien orientada la experiencia de la adopción tardía se puede presentar excelentes resultados.
\end{abstract}

Palabras clave: Adopción Tardía, Etapas de Convivencia, Psicoanálisis.

\section{Introdução aos aspectos gerais sobre a adoção}

Em tempos atuais, falar sobre adoção torna-se de suma importância não só pelo número de crianças e adolescentes disponíveis para esse processo, mas também pela necessidade de desmistificar alguns dogmas e esclarecer questões, sobretudo quanto à adoção tardia.

Bohnia (2010 citado por Souza \& Casanova, 2014) define a adoção como

um instituto que se estabelece a partir de uma relação voluntária, com fins a formar uma família, em que o afeto e a valorização são elementos importantes, pois a paternidade não é só genética ou biológica, mas psicológica, moral e sociocultural (p. 102).
Assim, tanto a maternidade como a paternidade podem ser desenvolvidas em qualquer fase da vida da criança ou do adolescente, pois para se tornar pai ou mãe, não é preciso que haja vínculo sanguíneo, mas sim afetivo.

O filho adotivo possui os mesmos direitos e deveres que o filho biológico, assim, são atribuídas aos pais por adoção as mesmas responsabilidades jurídicas, sociais e emocionais, como qualquer obrigação similar às de pais de um filho consanguíneo. O Estatuto da Criança e do Adolescente (ECA) estabelece, no artigo 40 , que qualquer pessoa maior de 18 anos, independente do estado civil, pode adotar, estabelecendo como restrições apenas a diferença mínima de 16 anos entre o adotante e o adotado e a impossibilidade de adotar irmão ou neto do adotante (Lei no 8.069, 1990). 
A adoção é um ato de comprometimento que exige dedicação, responsabilidade e amparo afetivo. Quando promovida de forma responsável, resulta em uma ação bem-sucedida, na qual ambas as partes encontram refúgio e oportunidade de suprirem suas necessidades - dos adotantes, de exercerem a paternagem/ maternagem e do adotado, de ter um ambiente familiar seguro, estável e com muito afeto para que possa se desenvolver de maneira saudável e feliz.

Camargo (2005a) informa que uma das maiores preocupações atuais tem sido a adoção, em razão do número significativo de crianças disponíveis para esse processo. Os dados estatísticos oferecidos pelo Cadastro Nacional de Adoção (CNA) revelam a triste realidade das crianças maiores acolhidas há anos, que aguardam uma família substituta (Conselho Nacional de Justiça, 2017). Segundo dados do CNA de 2017, havia 37.560 pretendentes habilitados, 7.624 crianças acolhidas e apenas 4.827 crianças disponíveis para adoção. Constatou-se que o número de crianças disponíveis para adoção cresce de modo significativo de acordo com a faixa etária, em contrapartida ao número de pretendentes que aceitam crianças maiores, que diminui consideravelmente e se mostra um obstáculo a essas adoções, uma vez que apenas $0,7 \%$ dos pretendentes aceitam adolescentes de 13 anos ou mais.

Por adoção tardia compreende-se a adoção de crianças a partir dos dois anos ou a partir dos três anos de idade, segundo a perspectiva de Souza e Casanova (2014). Entretanto, a adoção de crianças maiores não deve ser rotulada como tardia, e sim como essencial, pois essas crianças estão na fila de espera, na esperança de terem um lar e uma família para acolhê-las.

Souza e Casanova (2014), ao citarem a teoria de Chopra, ressaltam que os tipos de idade mencionados anteriormente concernem à idade cronológica. Assim, propõem que seja avaliada não apenas a idade biológica da criança/adolescente, que condiciona aparência física e sinais críticos da vida, mas também a idade psicológica, que engloba as vivências da criança. As idades biológica e psicológica muitas vezes não condizem com a cronológica, em virtude de a criança se desenvolver em um ambiente de negligências pela família ou em um ambiente de instituição, onde pode ter sido privada de estímulos necessários, afeto e relações familiares.

De acordo com pesquisa publicada pela revista britânica British Broadcasting Corporation (BBC) no mês de maio de 2016, dados comprovam a restrição em relação ao perfil almejado pelos pretendentes habilitados no CNA. O autor do estudo justifica os dados incongruentes com base em dois motivos: o primeiro se deve ao perfil restrito desejado pelos pretendentes, dos quais $84 \%$ optam por filhos com até cinco anos de idade, o que entra em choque com o dado de que $81 \%$ das crianças têm entre seis e dezessete anos; o segundo motivo refere-se à precária estrutura do setor público, caracterizado pela ausência de profissionais suficientes que atuem na vara da infância e da juventude para suprirem a demanda (Bernardo, 2016).

Bernardo (2016) explica que, em relação à restrição do perfil no CNA, a idade não é a única característica vista como um obstáculo para os pretendentes, pois há outros fatores que delimitam tais perfis, como condição de saúde, grupo de irmãos, etnia, gênero e cor da pele, contudo, a faixa etária sempre se sobressai dentre esses fatores.

O preconceito e os mitos em relação à adoção tardia não incidem somente nos pretendentes à adoção, mas sim na sociedade em geral, que rotula essas crianças e adolescentes conforme a faixa etária considerada avançada para adoção. Tais pensamentos distorcidos e preconceituosos refletem de modo significativo na não adoção desse grupo, resultando em uma quantidade exacerbada de crianças e adolescentes em unidades de acolhimento aguardando a reintegração a uma família substituta. Diante disso, observa-se a necessidade de esclarecimentos sobre tais mitos, que criam empecilhos à adoção dessas crianças/adolescentes.

A compreensão distorcida que a sociedade em geral tem a respeito dessas crianças e adolescentes inclui o histórico de vida pregresso do acolhido, o receio diante das famílias biológicas e o mito de que, após determinada idade, não há aquisição de novos hábitos, tampouco mudanças comportamentais, de forma que o sujeito já está pronto e estruturado e não pode ser moldado conforme os costumes e as crenças da família. Ademais, ainda há pessoas que confundem a medida de proteção do acolhimento institucional/ familiar com a medida socioeducativa de internação, aplicada aos adolescentes em conflito com a lei.

A adoção tardia muitas vezes é rotulada pela sociedade como uma adoção difícil, permeada de obstáculos e persistência, que frequentemente exige o enfrentamento dos preconceitos social e familiar. Assim, os pretendentes precisam se preparar e aceitar o histórico de vida de seu novo filho (Souza \& Casanova, 2014). Dessa forma, torna-se 
imprescindível orientar e preparar os pais que estão na fila de espera para adoção, mostrando as características psicológicas dos acolhidos e as fases de adaptação necessárias, pelas quais tanto o adotante como o adotado passam, e que podem contribuir para uma adoção bem-sucedida e para a quebra de tabus e crenças sem fundamentos.

As características psicológicas que envolvem as crianças e os adolescentes nessas situações são reflexo de seus históricos de vida, dos quais a maioria é marcada por uma bagagem emocional já violada, com rupturas, muitas vezes negligências, violações, abusos e abandono pela família biológica, que ocasionaram a perda do poder familiar. Após os pais perderem o direito sobre os filhos, a criança passa por um breve ou longo período na instituição de acolhimento, onde se depara com novas pessoas e regras e tende a se vincular novamente a outras crianças, pais sociais e cuidadores (Souza \& Casanova, 2014).

Esse período de institucionalização é um grande marco na vida dessas crianças que, mesmo com a pouca idade, já experimentaram o sentimento do abandono e a necessidade de adquirirem resiliência. Tais circunstâncias exigem maturidade, muitas vezes além da que a criança/adolescente possui, contudo, quando recebem o apoio técnico e psicológico necessário, superam as perdas e se preparam para novos vínculos de afeto.

Camargo (2005b) esclarece que é de suma importância que a criança elabore a fase do luto, em virtude das perdas afetivas do decorrer de sua vivência. Nesse período, tende a cicatrizar e amadurecer tais danos psicológicos, em preparação aos novos vínculos afetivos, inclusive o materno/paterno filial. Nesse sentido, torna-se evidente que, por ser sujeito em desenvolvimento, é possível e imprescindível a oportunidade de criar laços afetivos, como ocorre nas famílias por meio da adoção.

No momento em que a criança é encaminhada a uma nova família, ela passa pelo processo de desvinculação da instituição de acolhimento e estabelece uma nova vinculação, agora com a família adotiva. Ao se deparar com uma nova família, o infante precisa ter capacidade de resiliência, com o apoio de adultos, para conseguir conviver com novas pessoas, mudar de comportamentos e mentalidade, superar conflitos e ter liberdade emocional. Gomes (2003) acredita que, para uma adoção satisfatória, é necessário entender que "a afeição e a aceitação são necessidades psicológicas básicas que, se forem satisfeitas, produzem segurança emocional, garantindo a autoestima da criança" (p. 32).

Desse modo, a nova família deve se tornar um "porto seguro" para o filho, ser persistente, investir em tempo, ouvi-lo, conquistá-lo, ser firme e, ao mesmo tempo, amorosa. Ademais, as crianças saem das unidades de acolhimento muitas vezes com atrasos no desenvolvimento, o que requer atenção particular e disponibilidade constante dos pais para estimularem esse crescimento e, assim, vencerem mais um obstáculo (Souza \& Casanova, 2014).

Nesse período, o apoio técnico de profissionais comprometidos com o tema é essencial para dar o suporte necessário e fundamental para as novas famílias constituídas pela adoção. Para os adotantes, tais assistências são necessárias desde a fase da habilitação, durante o período de convivência e até o período pós-adoção. Em relação às crianças, em virtude de a demanda ser mais complexa, é imprescindível um trabalho desde quando chegam à instituição, ajudando-as no período de elaboração do luto da desvinculação da família biológica, no período da aceitação da família substituta, no período de convivência e no pós-adoção.

É defendido o conceito de que o meio essencial para uma adoção bem-sucedida deve incluir a preparação dos pretendentes e sua motivação que, nesse contexto, se refere ao desejo de exercer a maternidade/paternidade (Souza, 2012). Isso se justifica pelo fato de que quando a motivação do pretendente é inadequada, como altruísmo, substituição de um filho biológico, entre outras, o vínculo da filiação não se fortifica por causa da ausência de desejo adequado. Por conseguinte, pequenas dificuldades se tornam grandes problemas, culminando na devolução da criança ao abrigo, o que potencializa o sentimento de rejeição e abandono na criança, dessa vez pela família substituta (Riede \& Sartori, 2013).

Em face das questões e situações que obstaculizam a adoção dessas crianças e adolescentes, o objetivo geral do presente trabalho foi desfazer os mitos relacionados à adoção tardia, bem como compreender as características psicológicas e as fases de adaptação na adoção, visando identificar aspectos positivos e contrastar o vínculo afetivo entre o adotado e os pais adotivos. Para isso, optou-se pela metodologia de pesquisa bibliográfica e de campo, que foram seguidas por meio de entrevistas semiestruturadas, realizadas com 
pais adotivos de crianças enquadradas na faixa etária considerada como adoção tardia à época da realização da adoção, para a coleta de dados e informações relevantes acerca do estágio de convivência, bem como das dificuldades e assertividades em um processo do tipo. Ao final, foram comparados os resultados obtidos na pesquisa com o referencial teórico, o que proporcionou um contato importante com a realidade das adoções na esfera psicossocial, focada na visão de teóricos e na experiência dos pais por adoção.

$\mathrm{O}$ interesse pelo tema foi despertado após a vivência do estágio extracurricular no Fórum da comarca de Três Lagoas (MS), onde foi possível constatar a importância da preparação para a adoção frente às constantes dificuldades no estágio de convivência e aos casos de devoluções causadas por conflitos nessa etapa. Por meio do estágio voluntário e supervisionado no Grupo de Apoio à Adoção "Ato de Amor" (Graata), sediado no mesmo município e nele realizado, observou-se também o preconceito com crianças maiores disponíveis para adoção, pelo fato de os pretendentes preferirem crianças de até três anos, restringindo o perfil. Um dos estigmas vigentes está no fato de a adoção tardia ser constantemente considerada algo difícil, em razão da faixa etária da criança/adolescente e seu histórico de vida familiar e na unidade de acolhimento.

Assim, esta pesquisa visou compreender os aspectos psicológicos relacionados aos comportamentos das crianças/adolescentes e dos pais por adoção, comumente presentes no período de convivência pré-adotivo. Foram utilizados os métodos de pesquisa de campo, pesquisa qualitativa e embasamento teórico na psicanálise para a formulação do questionário diretivo. Com o intuito de organizar uma comparação entre a eficácia da teoria e a realidade da adoção, foram selecionados dois casais, que atenderam aos requisitos de terem efetuado uma adoção tardia e de possuírem pelo menos seis meses de convívio com a criança/adolescente.

O contato obtido com os casais selecionados ocorreu por intermédio da equipe técnica psicossocial do Fórum da comarca de Três Lagoas (MS) e eles foram submetidos à entrevista de modos diferentes. O primeiro casal foi entrevistado pessoalmente na Clínica Escola de Psicologia (Cepa) das Faculdades Integradas de Três Lagoas (AEMS) e o segundo casal foi submetido ao mesmo questionário via e-mail, em virtude de residir em outro município.
Cabe destacar que os casais foram colaborativos com a pesquisa, responderam às perguntas de modo claro e assinaram devidamente os termos de compromisso e aceitação da participação no projeto. Vale ressaltar, também, que a pesquisa foi submetida ao comitê de ética, tendo sua aprovação pela Plataforma Brasil (68189917.0.0000.5489).

É compreensível que, quando se fala de adoção, surgem muitas dúvidas e questões com relação a: personalidade, inseguranças, afetividade, expectativas e sobre a espera. Por isso, são válidos o esclarecimento e as desmistificações desses aspectos, além de ser extremamente importante ressaltar que é preciso que o adotante esteja preparado para o processo, tenha um desejo real pela adoção e, em especial, esteja bem consigo mesmo para conseguir zelar pelo adotado.

Em virtude da demanda exposta, é imprescindível a compreensão dos aspectos psicológicos e das fases de adaptação na adoção tardia das crianças/ adolescentes e dos adotantes frente a esse processo. Presume-se que, com o preparo e as informações adequadas, os pais terão o manejo assertivo para atingir o êxito no período de convivência e, então, consolidar uma adoção bem-sucedida.

\section{Características psicológicas e de adaptação de pais e filhos no estágio de convivência pré-adotivo}

Antes da homologação de fato da adoção da criança, ela deve passar por um período de adaptação e convivência com a nova família. O ECA preconiza, no artigo 46, que a adoção será precedida de estágio de convivência com a criança ou o adolescente, pelo prazo máximo de 90 dias, observadas a idade e as peculiaridades do caso (Lei no 8.069, 1990).

No decorrer dos trâmites, é fundamental que a equipe técnica tenha um olhar minucioso e avaliativo, tanto nas entrevistas psicológicas preliminares com os pretendentes quanto depois, no desenrolar do estágio de convivência, para se certificar de que a família está realmente atendendo às necessidades físicas e emocionais da criança/adolescente. Tal precaução se faz necessária para que consigam constatar o verdadeiro desejo perante a adoção e o estado emocional dos envolvidos. Em contrapartida, em razão das mudanças de rotina e da nova referência familiar, a criança/adolescente pode apresentar resistência aos pais, ou até mesmo deslocamento de personalidade, pois deseja agradar as novas figuras parentais. 
Essa situação também possibilita sentimentos de ambivalência, ocasionando comportamentos de rebeldia e de testagem (Alvarenga \& Bittencourt, 2013).

Em seu estudo e análise referente ao período de convivência, Campos (2016) identificou quinze comportamentos infantis comumente presentes nas adoções tardias com o intuito de preparar os pais por adoção que desejam construir a filiação parental com crianças maiores. Vale ressaltar que essas fases comumente presentes no desenrolar do estágio de convivência e as características expostas a seguir, em razão da singularidade das dinâmicas familiares e da criança/ adolescente, não estão fielmente presentes em todos os casos. As quinze características gerais são:

a) Surgimento de comportamentos regressivos na criança: nesta fase, há uma regressão no comportamento da criança em relação a seu desenvolvimento, como voltar a ter enurese noturna, voltar a mamar, tentar renascer da barriga da mãe adotiva por meio de fantasias e brincadeiras, pois sente a necessidade de voltar ao estágio de recém-nascido e ter a família substituta como biológica. Isso funciona como um resgate das fases importantes, na tentativa de revivê-las com as novas figuras parentais.

b) Agressividade: logo após da fase do encantamento, ocorre a eclosão de atos agressivos manifestados de forma física ou verbal. Neste período, a criança apresenta oposição às regras e insegurança pelo receio de um novo abandono, ocasionando contradição em seus próprios sentimentos. É importante lembrar que, muitas vezes, a criança adquire comportamento agressivo para se defender no período do acolhimento ou como um sinal de que o luto pela perda do vínculo com as cuidadoras do abrigo ainda não foi elaborado. Ajuda muito quando a família adotiva estabelece as regras familiares, os limites e as figuras de autoridade, sendo fundamental nessa fase que os novos pais tenham paciência e sejam firmes. Nestes casos, é recomendada a realização de acompanhamento psicológico para ajudar a criança nessa elaboração de sentimentos, expressões e adaptações necessários.

Winnicott (1982) enfatiza que quando a criança se desenvolve em um ambiente favorável às suas necessidades psicológicas e biológicas de modo equilibrado, consegue elaborar naturalmente essa fase. Porém, ao crescer em um ambiente que não oferece os cuidados necessários para avançar nessa etapa, a agressividade ocorre com maior intensidade e, como consequência, prejudica seu desenvolvimento saudável.

c) Agressividade, em particular contra a mãe adotiva: nesse caso, a criança fantasia a mãe biológica na adotiva e, então, começa a agir como se fosse esta que a abandonou. Diante dessa dificuldade de entender e temer um novo abandono, comportamentos hostis começam a ser mais frequentes, trazendo regresso emocional e levando a criança a agir de forma mais instintiva e primitiva, expressando em seu meio atual o que viveu no passado. Ou seja, se foi violada ou abandonada, esses sentimentos remetem aos pais biológicos.

d) Ritmo acelerado do desenvolvimento global da criança: essa característica é extremamente positiva e ocorre em ritmo acelerado. Esse desenvolvimento global da criança/adolescente acontece graças ao novo ambiente familiar, pois a criança recebe os cuidados necessários de forma individual, o que é muito satisfatório para o desenvolvimento infantil, diferente do cuidado coletivo que recebia na instituição de acolhimento. Nessas circunstâncias, a criança/adolescente apresenta evolução nos estímulos motores, cognitivos e sociais, o que potencializa sua autoestima e seu valor social e atende também às expectativas da família.

É importante ressaltar que nem sempre a criança será capaz de atender todas as expectativas idealizadas pelos pais, em virtude da singularidade humana. Então, os passos mais importantes a respeito da adoção são a busca por preparo adequado e por conhecimento, o imprescindível respeito pelo histórico de vida da criança/ adolescente e a aceitação do filho e de todas as suas características pessoais.

e) Enfrentamento do preconceito social: esse momento é extremamente prejudicial para a dinâmica da família, pois muitas vezes o fato de a sociedade - e até mesmo a família extensa dos pais adotivos - fazer especulações sobre a criança/adolescente e não aceitá-la de fato como um novo integrante da família faz os medos, as inseguranças e os receios da criança/adolescente novamente virem à tona. Campos (2016) ressalta a importância e o resultado positivo, nesta fase, de os pais frequentarem o grupo de apoio à adoção e receberem o suporte necessário da equipe técnica. 
f) Esforço significativo da criança para se identificar com os novos modelos parentais: ocorre quando a criança/adolescente tenta se esforçar de modo significativo para se identificar com os novos modelos parentais e os demais membros da nova família, mediante imitações, com o objetivo de encontrar características comportamentais ou físicas semelhantes. Em contrapartida, nessa fase, pode ocorrer também agressividade verbal da criança em dizer aos pais que eles não são seus pais.

g) Construção do vínculo de filiação com atropelamento de etapas: sabe-se que para a filiação se concretizar, não é necessário que haja vínculo sanguíneo, e sim afetivo, que então poderá resultar em um relacionamento materno/paterno filial. Na adoção tardia, os obstáculos e os laços de afeto ainda estão se fortificando, o que põe à prova se a motivação do casal para adotar era realmente se tornarem pai e mãe e se a criança elaborou por completo o luto pela família biológica. Essas situações podem atrapalhar a formação de vínculos entre a família. Portanto, quando pais e filhos conseguem superar essa fase, o vínculo de afeto se fortifica ainda mais.

h) O vínculo afetivo pode ocorrer de forma diferenciada: os membros da família se identificam e demonstram sentimentos de modo diferente. É natural que o filho se identifique mais com um dos pais e expresse mais afetividade por ele, o que ocorre também nos relacionamentos fraternais. Nesta fase, Campos (2016) menciona a adoção de grupo de irmãos, explicando que é comum que os pais se vinculem mais rápido com crianças mais novas ou com crianças/adolescentes que demonstrem mais afeto, o que pode culminar em dúvidas relacionadas à adoção das crianças maiores e menos afetivas. Em contrapartida, demonstrar afeto e sentimentos não deixa de ser um aprendizado e, por meio da convivência e dos exemplos, as crianças/adolescentes podem passar a ter comportamentos mais afetuosos.

i) e j) Aquisição de novos hábitos e de novos costumes alimentares: é necessário que a família compreenda que a criança/adolescente chega com seus costumes e manias. Então, para que o convívio não perca a harmonia, é preciso empatia recíproca, especialmente por parte dos pais, pois pode ser muito difícil para a criança adquirir novos hábitos e rotinas familiares. No caso de hábitos alimentares, após a fase da "lua de mel", em que as crianças/adolescentes querem agradar a nova família, é normal que comecem a negar determinados tipos de alimentos, a ponto de se tornar exaustivo para os pais precisar insistir e brigar com a criança/adolescente diariamente para que tenha uma alimentação saudável e variada. Destarte, nesta fase, são essenciais a paciência e a persistência.

k) A criança constrói um "novo eu": ela faz o uso de fantasias relacionadas aos pais biológicos e adotivos diante das situações que considera negativas na família adotiva. Imagina que os pais biológicos irão salvá-la ou idealiza os pais adotivos como os pais biológicos, negando seu histórico de vida, inclusive o período de institucionalização. Esses momentos fantasiosos, ainda que pareçam confusos, são necessários para o processo de reconstrução do ego daquela criança. A criança apresenta também sentimento de invulnerabilidade, ou seja, imagina-se como "super-herói”, o que é positivo para o desenvolvimento da segurança.

1) Mobilização de emoções intensas e carregadas de ambivalência: neste caso, ambos possuem sentimentos contraditórios de raiva e amor, porém, cabe aos pais trabalhar essa questão com mais facilidade, pois tem maior maturidade emocional para se conterem.

m)Sentimentos de vulnerabilidade, impotência e culpa: neste estágio, esses sentimentos podem se manifestar nos pais, por se considerarem na obrigação de serem perfeitos, o que os leva a exercer uma autocobrança desmedida e desnecessária. É comum também que os pais sintam culpa ou gratidão pela criança e pela família biológica.

n) A criança se mostra muito imatura perante uma situação e muito avançada frente a outras: isso ocorre tendo em vista que, por causa das experiências de vida, ela precisou amadurecer em alguns aspectos em detrimento de outros, mesmo não sendo o esperado para sua faixa etária.

o) Enfrentamento da curiosidade e do preconceito social: neste momento, os pais e filhos ficam extremamente cansados em razão das perguntas invasivas sobre a falta de semelhanças, resultando na necessidade de provar o verdadeiro vínculo entre eles e o filho adotivo (Campos, 2016). 
Petta e Steed (2005 citados por Huber \& Siqueira, 2010) relatam que os pais adotivos enfrentam processos de construção e aceitação para assumirem a identidade de pais, de forma que é exigido o cumprimento de etapas internas para conseguirem exercer seus papéis corretamente. Porém, esse processo de autoconhecimento e de ascensão da identidade de pai ou mãe pode ser dificultoso, pois envolve diversos sentimentos, como o de estar em competição com os pais biológicos, o que resulta na insegurança de que a criança/adolescente ame mais seus pais biológicos do que os adotivos. Partindo desse pressuposto, é necessário compreender que se esse temor for acionado diversas vezes, pode afetar a relação e o sucesso dos pais por adoção com o filho, uma vez que a segurança da nova relação parental deve partir dos pais para que a vinculação parental ocorra.

Bowlby (2015) define a vinculação afetiva como resultado do comportamento social de cada indivíduo e da capacidade de reconhecer o outro e se aproximar dele. Assim, para que a vinculação afetiva ocorra integralmente, é necessária a reciprocidade nos laços de afeto. Em contrapartida, indivíduos que não receberam os cuidados necessários na infância sofrem pela ruptura de vínculos afetivos, o que prejudica a capacidade de novos apegos. Eventos como morte, separação conjugal ou ausência dos pais podem desencadear consequências emocionais decorrentes da falta de vinculação, como resistência perante o afeto, a agressividade e os transtornos de personalidade. Portanto, são necessárias a persistência e a paciência por parte dos pais por adoção com os filhos, uma vez que eles carregam históricos de abandono, negligências afetivas e rupturas de vínculos de afeto que vão ao encontro da teoria mencionada.

Schettini Filho (2017) ressalta a importância do acolhimento na filiação adotiva, pois a transição do vínculo da família biológica para a família substituta se dá de acordo com o modo como a família acolhe o filho. O autor enfatiza que esse acolhimento e a posterior convivência devem ser permeados de persistência, esperança e paciência por parte dos pais para com a criança/adolescente. Quando a criança observa o amor incondicional dos pais por ela, demonstrado pelas atitudes persistentes, o vínculo filial se consolida. Contudo, o tempo da criança muitas vezes não coincide com o dos pais. Por isso, em algumas situações, a persistência pode se tornar exaustiva para os adultos, momento em que a preparação dos pais fica evidente.
Segundo Mendes e Santos (2014), a construção da personalidade é um processamento difícil, caracterizada pela relação psicossocial contínua e influenciada por processos conscientes, inconscientes e dinâmicos. Isto é, a personalidade se forma com aspectos psicológicos do indivíduo e das relações sociais, considerando lembranças conscientes e inconscientes, de forma que a personalidade está em constante evolução. No entanto, a sociedade crê que após os seis anos de idade, a criança se torna muito resistente à aquisição de hábitos e de referências familiares, visto que conforme tal senso comum sua personalidade já está moldada e constituída. Isso se dá em virtude de uma leitura errônea da obra de Freud, na qual ele define que na primeira infância é construída a estrutura psíquica, e não as características individuais e a identidade, que são formadas e alteradas no decorrer das experiências do sujeito.

Diante disso, quando os futuros pais ainda são pretendentes à adoção, devem obter informações para desmistificar as idealizações sobre o gesto e compreender que é indispensável formar uma família que provenha saúde psíquica e afeto. Além disso, os adotantes devem disponibilizar dedicação total ao filho, pois a criança/adolescente precisa se sentir amparada e desejada pela nova família para que erradique qualquer possibilidade de insucesso na adoção.

A adoção tardia possui uma complexidade maior, especialmente na fase de adaptação, em virtude de dificuldades no início do convívio, por ser o momento de conhecimento, criação e fortalecimento de vínculos de afeto entre adotantes e adotado. A preparação dos pais e o modo como agem nesse período são fatores relevantes para que a adoção obtenha êxito no futuro.

Assim, quando os pais têm a preparação adequada e o conhecimento das fases de adaptação abordadas anteriormente, terão maior compreensão sobre os aspectos psicológicos que envolvem a criança, entenderão seus comportamentos e poderão agir com mais assertividade, de acordo com a demanda do filho. Pois ao se depararem com determinadas situações, serão capazes de compreender que aquele comportamento é natural e, então, tomar uma atitude correta e agir com paciência e naturalidade. Em contrapartida, pais sem a preparação e o conhecimento de tais aspectos podem sentir maior dificuldade para lidar com as situações por não compreenderem o que está se passando, o que pode resultar no insucesso da adoção, gerando a desistência dos pais por esse filho e culminando na devolução da criança à unidade de acolhimento. 


\section{Resultado e discussão}

A pesquisa foi realizada com dois casais heterossexuais que adotaram e se encontravam no período de convivência de seis meses a um ano, aqui denominados de família 1 e família 2 . O casal da família 1 , com 31 e 34 anos de idade, realizou o curso preparatório à adoção; já o casal da família 2, com 43 e 39 anos de idade, não realizou o curso preparatório à adoção.

A família 1 não teve muitas dificuldades no estágio de convivência e adotou mais de uma criança, primeiramente S. e depois sua irmã. Por outro lado, a família 2, que não participou do curso em virtude de não ser oferecido no município, manifestou a necessidade de buscar outros meios de informação como auxílio psicológico, consulta a livros, artigos e páginas de fácil acesso na internet relacionadas à adoção - para conseguir lidar com as dificuldades desse período. Por intermédio desses recursos de acesso ao conhecimento sobre o tema, ambas as famílias obtiveram êxito na adoção e na internalização das novas figuras parentais pela criança em um curto período.

O grupo de apoio nos ajudou muito a obter informações e a aumentar ainda mais a faixa etária do nosso perfil para adoção. Porém, achávamos que adoção era ir no orfanato escolher uma criança que se identifica e levar embora e com o curso percebemos que o processo não era assim (Família 1).

Por meio da pesquisa de campo, constatou-se a relevância e o reconhecimento quanto ao momento da preparação dos futuros pais por adoção, pois com o preparo adequado, os pais não se surpreendem com tanta intensidade quando a criança apresenta comportamentos de testagem e oposições, além de saberem como agir diante dessas situações, como observado nas entrevistas.

Tenho certeza que um curso com os pretendentes aprofundando as dificuldades do processo, falando sobre a realidade enfrentada no dia a dia ajudaria bastante os casais. Entender as dificuldades pelas quais as outras pessoas passam nos traz tranquilidade porque nós entendemos que é um problema comum e geral e não somente conosco. Depois da adoção eu (esposa) particularmente lia muitos artigos a respeito do assunto (que foram bastantes esclarecedores e que me trouxeram calma em momentos de dificuldades). Já fazia terapia e isso me ajudou bastante a lidar com as dificuldades que iam surgindo. Depois, como família procuramos terapia para nos ajustarmos (Família 2).

Sobre a questão da idade, observa-se que, como participou do curso preparatório, a família 1 pôde reavaliar seus critérios para adoção, especificamente em relação à idade.

Com o curso a gente foi vendo que não tinha muito a ver a idade, mas o que importava era a criança, a idade não faria diferença, eu não iria deixar de ser mãe, e nem ele de ser pai se a criança não fosse tão pequena. Então foi aí que mudamos radicalmente o perfil, de um até dez anos (Família 1).

À vista disso, os grupos de apoio à adoção foram apontados como ótimos instrumentos para esse processo, pois, por meio deles, os pretendentes e pais esclarecem dúvidas, aprendem sobre o tema e compartilham seus anseios e os mitos envoltos na temática, além de terem acesso a testemunhos de famílias constituídas pela adoção, com suas experiências e frustrações. Desse modo, as dificuldades e potencialidades que envolvem o universo da adoção se tornam naturais para essas pessoas.

Assim, constata-se que o material teórico utilizado no trabalho corroborou as informações e os dados fornecidos pelas famílias. Os mesmos comportamentos típicos apresentados por crianças adotadas na faixa etária da adoção tardia foram constatados nos casos.

Acreditamos que elas nos testam sempre, mas teve um episódio, por exemplo, que uma delas bateu em um colega da escola e fomos chamados, vimos ali que ela queria ver se iríamos desistir dela ou se continuaríamos com ela. Como a S. foi a primeira que adotamos, ela fazia muita birra, chorava muito e não conversava, porque sentia muita falta das irmãs, então a grande angústia era a saudade das irmãs, mas depois melhorou (Família 1).

A família 2 também corroborou as questões apresentadas pela família 1 em relação às fases de testagem das crianças.

Ele apresentou fases de testagens e muitas birras. Logo de início ele já mostrou para nós quem ele era de fato. Até hoje ele ainda faz birras, embora elas 
tenham diminuido significativamente. . . Chegar a uma casa nova e lidar com a realidade foi dificil, em especial para ele. Ele estava vindo para uma casa estranha, escola estranha, sem amigos, deu bastante trabalho na escola (não estava alfabetizado), fazia muitas birras para ir para aula, para estudar. Foi bem desgastante! Ele fazia birras diárias para ir para escola por uns dois meses. Até que um belo dia elas acabaram (só as da escola, risos). Tivemos que colocá-lo no reforço, com muita dedicação e empenho nosso, dele e dos professores ele está alfabetizado. Já está conseguindo acompanhar a classe. Eé um bom aluno (Família 2).

A assertividade dos pais e a não revitimização das crianças foram vistas como outro fator positivo. Os pais consideram a bagagem emocional da criança, porém, explicam ao filho que, a partir da adoção, a criança passa a ter vida nova e educação pautada nas crenças e exemplos da nova família. Desse modo, ambas as famílias não consideraram o histórico da criança como um motivo para superproteger o filho e deixar de oferecer limites e disciplina, o que também é importante para a formação de vínculos de afeto e para a transmissão de segurança à criança.

O que não pode faltar é ordem, e sempre a verdade, estimulamos o diálogo entre nós e nos preocupamos com quem conversam, o que fazem e principalmente nos preocupamos sempre em colocar limites. Cada dia que passa se parecem cada vez mais conosco, mas no início falavam muito sobre suas histórias de vida de forma negativa, mas sempre falamos que não nos importamos com a história delas, falamos que tudo que elas fizeram lá atrás, fica lá! Pois estamos aqui oferecendo um recomeço e que não nos importa o passado delas e que agora a gente tem que focar no agora em diante, o resto ficou para trás. . . . Eu acho que a adoção em casa dá certo, porque a gente joga muito limpo, não fica fantasiando as histórias, a gente senta na mesa, perguntamos o que está acontecendo e deixamos elas tirarem suas dúvidas também, acreditamos na ordem e sempre na verdade entre nós (Família 1).

No entanto, consideramos que é importante a família levar em conta o histórico de vida da criança/ adolescente antes do período de adoção, não no sentido de rotular e estigmatizar suas experiências, mas sim de compreender sua trajetória de vida e as marcas impressas em sua subjetividade que a constituíram enquanto sujeito. Assim, não convém desconsiderar e anular a trajetória de vida desse sujeito.

Para obter êxito, é necessário que tenhamos paciência, determinação, perseverança, coragem, foco e vontade de acertar, ficamos desesperados em vários momentos, inseguros, sem saber se estávamos agindo de forma adequada, mas o amor, o carinho, a compreensão e o tempo resolvem tudo. Ele mudou tudo em nossa vida, nossa vida não mais nos pertence. Todas as decisões tomadas giram em torno do nosso filho (Família 2).

Quanto aos mitos, preconceitos e pensamentos distorcidos de que as crianças maiores têm a personalidade formada e são incapazes de internalizar novas figuras parentais e de adotar novos comportamentos, com base nos casos reais entrevistados, torna-se evidente que isso é apenas mais um mito comum da adoção tardia.

Achamos bem esquisito no começo, era tudo muito novo, muito estranho, porque logo no primeiro dia já estavam me chamando de mãe. Eu também ficava muito insegura, escondia a chave de casa com medo delas fugirem no meio da noite. . . . Os casais ficam preocupados se os filhos adotados irão se parecer com eles, por isso resolvem pegar bebês, mas as minhas filhas tentam me imitar muito para se parecerem comigo também, até no jeito de falar, então o importante é como se educa e não se é bebê (Família 1).

Um episódio mexeu bastante comigo (esposa). Já no primeiro encontro, estávamos nadando na piscina de um hotel onde foi realizado o encontro e tinha uma outra criança desconhecida nadando junto, que começou a brincar com ele. Num determinado momento essa criança perguntou para ele quem eu era... ele respondeu 'minha mãe'... daqui a pouco pensou... 'minha tia, mas daqui a pouco vai ser minha mãe'. A menina, menor, sem entender nada, perguntou: mas como assim? Ela tá grávida? E ele responde com uma maturidade impar: só se estiver grávida de mim... porque sou eu quem vou nascer dela (Família 2). 
A adoção é um ato de amor, e é fundamental que esse processo seja recíproco, visto que antes de a criança adotar os novos pais, estes devem adotá-la como filha e transmitir essa posição e segurança a ela, até perante as dificuldades. Mesmo diante dos obstáculos, preconceitos e mitos, a adoção tardia, quando desejada por ambos os envolvidos, pode sim ter um final feliz. Cabe destacar que todos os entrevistados asseguraram que seus filhos adotaram novos hábitos e comportamentos, se esforçam para se identificar com os pais, construíram vínculos de afeto de modo acelerado, se referiram aos casais como pai e mãe em um curto prazo de tempo, internalizaram as novas figuras parentais e foram, para a surpresa dos adultos, rapidamente capazes de construir um "novo eu", o que comprova o dinamismo da personalidade.

Por fim, tornou-se claro que, por sermos seres humanos em constante desenvolvimento, nunca é tarde para a criação de novos vínculos de afeto, inclusive o da filiação afetiva. Uma vez que a vontade e necessidade dessas crianças de receberem afeto, cuidados individuais e referência familiar são prementes, a adoção, por parte da própria criança, se dá mais rapidamente do que os adultos esperam, como demonstram os excertos de entrevistas a seguir:

Fiquei muito assustada, no primeiro dia já me chamavam de mãe, e aquilo me assustou muito, porque foi muito de repente, mas mesmo tímidas já percebíamos a aceitação delas (Família 1).

A adoção dele por nós foi imediata, logo você percebia que ele já queria nos chamar de pai e mãe, nós é que éramos mais relutantes quanto ao assunto com medo de criarmos na criança uma expectativa frustrada (Família 2).

A análise e a discussão dos dados obtidos por meio da pesquisa de campo permitiram explanar que os mitos e preconceitos existem no universo da adoção, mas quando há a desmistificação desses pensamentos distorcidos e a preparação adequada dos pretendentes, a probabilidade de êxito da filiação afetiva é muito maior, como observado nas entrevistas realizadas.

\section{Considerações finais}

Os resultados obtidos com a pesquisa de campo permitem concluir que a teoria exposta corroborou as informações colhidas nas entrevistas. Tornaram-se nítidos os comportamentos apresentados pelas crianças que são adotadas na faixa etária caracterizada como adoção tardia, bem como a importância da preparação e dos instrumentos aos quais as famílias podem ter acesso para que consigam agir de modo assertivo e, então, ter uma adoção eficaz.

Souza (2015) enfatiza que a adoção tardia é sim complexa, porém, com a preparação e o manejo assertivo da nova família, é possível que seja bem-sucedida e haja a internalização das novas figuras parentais pela criança. A autora menciona aspectos da criança/adolescente que indicam uma adoção eficaz, como: elevação da autoestima, melhora do vocabulário, saúde física e mental, demonstração afeto e gratidão, associação a comportamentos da família, sorrisos mais frequentes, demonstração de medo de voltar para a instituição e preocupação em ser bom filho para continuar com a família.

Ademais, quando uma criança/adolescente tem a oportunidade de criar laços afetivos com figuras de cuidadores relevantes, como mães e pais, essa relação reflete de modo satisfatório no psiquismo desse filho, pois a nova família se torna um aparato psíquico para a criança. Há que se destacar que as relações de apego constituem um dos mais significativos componentes da personalidade (Camargo, 2005b).

Os aspectos psicológicos de pais e filhos elencados no referencial teórico foram evidentes na pesquisa em campo, e mesmo em face de todas as dificuldades decorrentes do desenvolvimento infantil e do histórico de vida da criança, conclui-se que o afeto e a adoção recíproca prevalecem sobre qualquer desafio.

No que tange à preparação dos futuros pais, no estudo realizado, constatou-se que cursos de apoio à adoção são ótimas estratégias para findar preconceitos, rótulos e crenças distorcidas presentes na sociedade, até mesmo entre futuros pais, a respeito da adoção. Ademais, tal preparação foi vista como um grande instrumento de aprendizado sobre a realidade do universo da adoção, o que prepara os futuros pais para os possíveis desafios.

Entretanto, como os cursos preparatórios não são realidade em todas as cidades, surge a necessidade de os pais que não receberam o suporte técnico procurarem orientação profissional e conhecimento sobre a adoção por meio de livros, artigos e vídeos de fácil acesso na internet, para que, assim, as adoções dessas famílias tenham a mesma probabilidade de êxito das que receberam a preparação necessária. 
Salienta-se que, mesmo diante de todos os preconceitos e mitos em relação à adoção, em especial à adoção de crianças maiores, enraizados na nossa cultura, o presente trabalho esclareceu que é sim possível consolidar uma adoção tardia com final feliz e estabilidade de vínculos de afeto, análogos ao paterno e materno filial. Destarte, destaca-se que a filiação consanguínea perde seu valor diante da filiação afetiva.

\section{Referência}

Alvarenga, L. L., \& Bittencourt, M. I. G. F. (2013). A delicada construção de um vínculo de filiação: O papel do psicólogo em processos de adoção. Pensando Famílias, 17(1), 41-53.

Bernardo, A. (2016, 10 de maio). Por que 36 mil pais não conseguem adotar 6,5 mil crianças em abrigos. BBC Brasil. http://www.bbc.com/portuguese/brasil/2016/05/160509_adocao_criancas_ab

Bowlby, J. (2015). Formação e rompimento dos laços afetivos. Martins Fontes.

Conselho Nacional de Justiça. (2017). Cadastro Nacional de Adoção. https://www.cnj.jus.br/cnanovo/pages/ publico/index.jsf

Camargo, M. L. (2005a). A adoção tardia no Brasil: Desafios e perspectivas para o cuidado com crianças e adolescentes. 2o Simpósio Internacional do Adolescente, São Paulo, SP, Brasil. http://www.proceedings.scielo.br/scielo.php? script=sci_arttext\&pid=MSC0000000082005000200013\&lng=en\&nrm=abn

Camargo, M. L. (2005b). Adoção tardia: Representações sociais de famílias adotivas e postulantes à adoção (mitos, medos e expectativas) [Dissertação de mestrado, Universidade Estadual Paulista]. Repositório Institucional Unesp. https://repositorio.unesp.br/bitstream/handle/11449/97679/camargo_ml_me_assis.pdf

Campos, N.M.V. (2016). Adoçãotardia:Característicasdoestágiodeconvivência.Tribunalde Justiça do Distrito Federal e dos Territórios. https://www.tjdft.jus.br/informacoes/infancia-e-juventude/publicacoes-textos-e-artigos/ textos-e-artigos/adocao-tardia

Gomes, M. R. (2003). Adoção: Aceitar a criança e sua história condição essencial para seu sucesso [Trabalho de Conclusão de Curso, Centro Universitário de Brasília]. Repositório Institucional Ceub. https://repositorio. uniceub.br/jspui/bitstream/123456789/3047/2/9982077.pdf

Huber, M. Z., \& Siqueira, A. C. (2010). Pais por adoção: A adoção na perspectiva dos casais em fila de espera. Psicologia: Teoria e Prática, 12(2), 200-216.

Lei n. 8.069, de 13 de julho de 1990. (1990, 16 de julho). Dispõe sobre o Estatuto da Criança e do Adolescente e dá outras providências. Diário Oficial da União. http://www.planalto.gov.br/ccivil_03/LEIS/L8069.htm

Mendes, T. S., \& Santos, V. Z. (2014). Acolhimento de crianças e jovens em perigo. Climepsi.

Riede, J. E., \& Sartori, G. L. Z. (2013). Adoção e os fatores de risco: Do afeto à devolução das crianças e adolescentes. Perspectiva, 37(138), 143-154.

Schettini Filho, L. (2017). As dores da adoção. Juruá.

Souza, H. P. (2012). Adoção tardia: Devolução ou desistência de um filho? A necessária preparação para adoção. Juruá.

Souza, H. P. (2015). Pós-adoção: Depois que o filho chegar. Juruá.

Souza, H., \& Casanova, R. (2014). Adoção e a preparação dos pretendentes: Roteiro para o trabalho nos grupos preparatórios. Juruá.

Winnicott, D. W. (1982). Raízes da agressividade. In D. W. Winnicott, A criança e seu mundo (6a ed., pp. 262-270). LTC.

\section{Juliana Fernanda de Barros}

Doutora em Psicologia pela Faculdade de Ciências e Letras de Assis da Universidade Estadual Paulista (Unesp), Assis - SP. Brasil.

E-mail: julianafernanda@msn.com

(1) https://orcid.org/0000-0001-5318-872X 
Priscila Weiler Ribeiro

Especialista em Neuropsicologia (INDEP) e Psicóloga na Equipe Multidisciplinar de Prevenção ao Acolhimento (EMPA), Três Lagoas - MS. Brasil.

E-mail: priscilaweiller@hotmail.com

(1) https://orcid.org/0000-0003-0523-4685

Lorena de Freitas Souza

Bacharel em Psicologia pelas Faculdades Integradas de Três Lagoas (AEMS), Três Lagoas - MS. Brasil.

E-mail: psicolorena.souza@gmail.com

(1) https:// orcid.org/0000-0002-9799-9652

Endereço para envio de correspondência:

Rua Álvaro da Fonseca, 474, Umuarama. CEP: 16013-090. Araçatuba - SP. Brasil.

Recebido 08/10/2018

Aceito 02/03/2020

Received 10/08/2018

Approved 03/02/2020

Recibido 08/10/2018

Aceptado 02/03/2020

Como citar: Barros, J. F., Ribeiro, P.W., \& Souza, L. F. (2021). Os aspectos psicológicos da criança e do adolescente na adoção tardia. Psicologia: Ciência e Profissão, 41 (n.spe 3), 1-13. https://doi.org/10.1590/1982-3703003215129

How to cite: Barros, J. F, Ribeiro, P. W., \& Souza, L. F. (2021). psychological features of late-adopted children and adolescents. Psicologia: Ciência e Profissão, 41 (n.spe 3), 1-13. https://doi.org/10.1590/1982-3703003215129

Cómo citar: Barros, J. F., Ribeiro, P. W., \& Souza, L. F. (2021). Los aspectos psicológicos del niño y del adolescente en la adopción tardía. Psicologia: Ciência e Profissão, 41 (n.spe 3), 1-13. https://doi.org/10.1590/1982-3703003215129 